مسعود نصيرى * (دانشجوى دكترى)

محمد حاجى عزيزى (دانشيار)

دانشكدهى فنى مهندسى، دانشعاه رازي (داري)

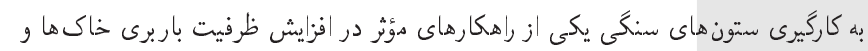

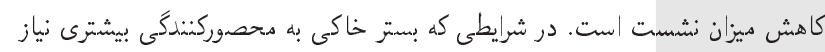

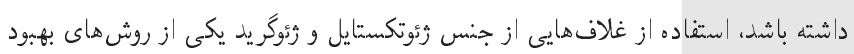

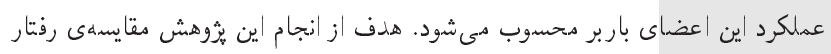

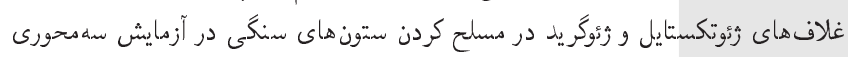

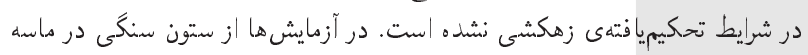

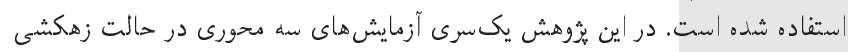

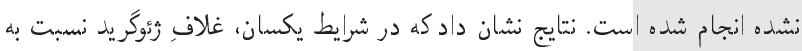

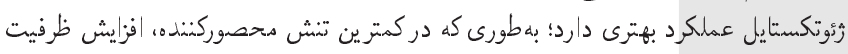

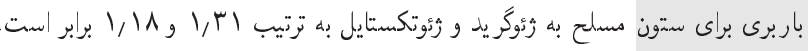

nasiri.ma@razi.ac.ir

وازگان كليدى: ماسه، ستون سنكى، غلاف زئوسنتيكى، آزمايش سهمحورى.

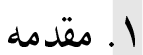

و همجنين كمتر شدن ميزان خمرهيى شدن اين اعضا هشمگيرتر خواهد بود. نتايج

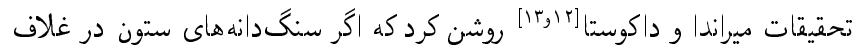

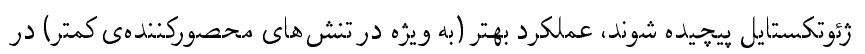

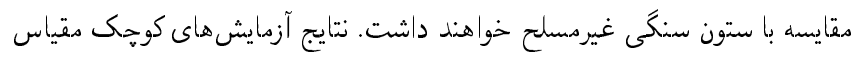

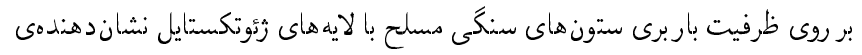

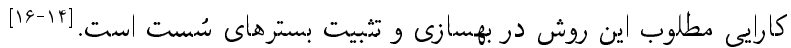

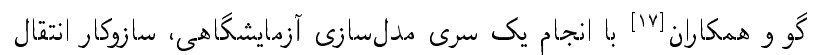

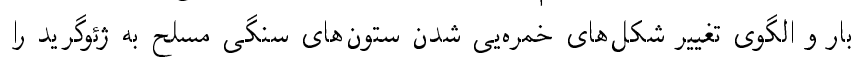

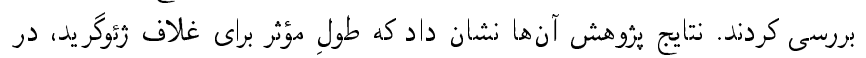

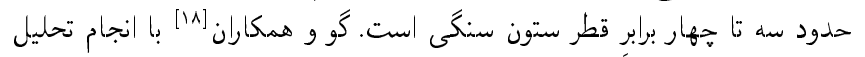

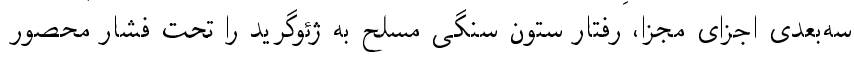

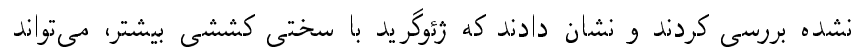

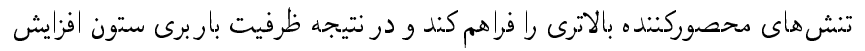

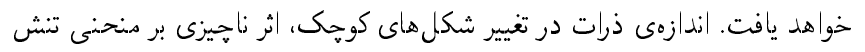

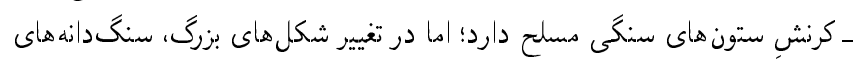

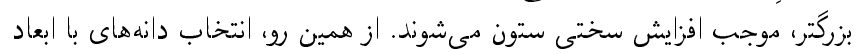

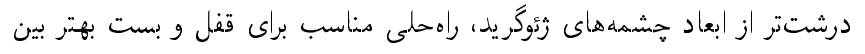

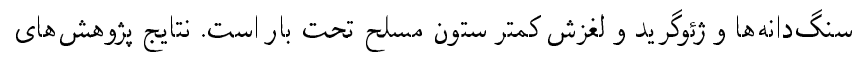

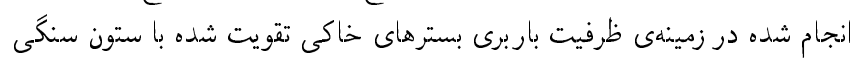

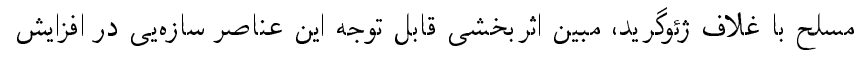

استفاده از ستونهاى سنكى در بسترهاى خاكى يكى از روشهاى كاربردى براى

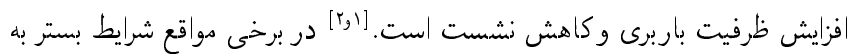

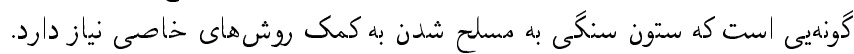

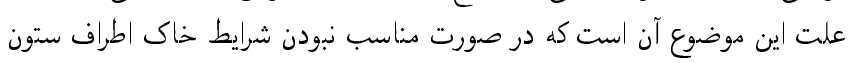
سنكى، به دحصوركندگى بيشترى براى ستون سنكى احتياج است تا عملكرد فرايند

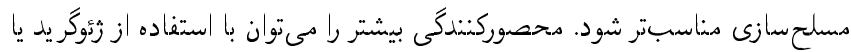

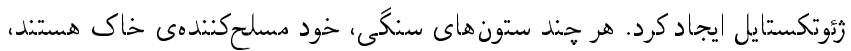

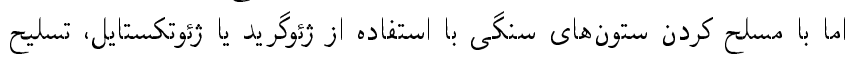
خاك افزايش مىيابد. از جملهى اين روشها مىتوان به ايجاد صلبيت در ستون هاى سنكى (استفاده

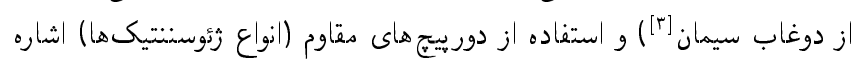

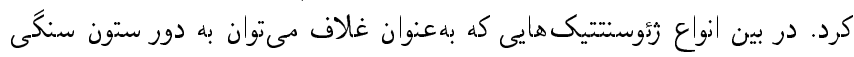

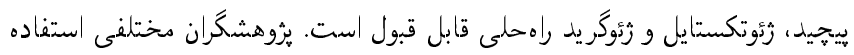

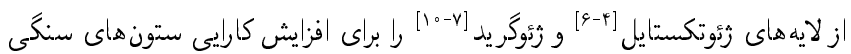

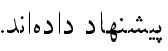
نتايج نيروهشهاى زانگ و رائو[1'] مشخص كرد كه هرقدر سختى غلاف

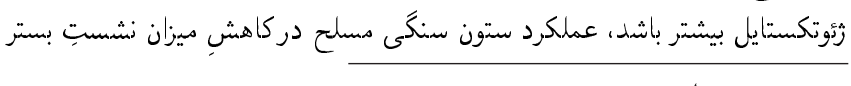
* تويسنده مسئول

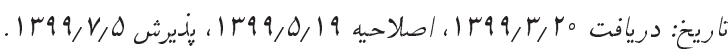
DOI:10.24200/J30.2020.55894.2788 


\begin{tabular}{|c|c|}
\hline \multicolumn{2}{|r|}{ جدول 1. مشخصات ماسه. } \\
\hline$V, Y M I$ & ضريب يكنواختى (Cu) \\
\hline 1,010 & ضريب انحنا (Cc) \\
\hline SW & نام خاك در سيستم طبقهبندى متحد \\
\hline$r, 990$ & جֶَالى ويزه (Gs) \\
\hline 0,099 & نسبت تخلخل بيشينه (e \\
\hline $0, r \Delta r$ & نسبت تخلخل كمينه (e \\
\hline$r \circ, v$ & زاويهى اصطكاك (')(ب) \\
\hline$\approx 0$ & جسبندگى (كيلوياسكال) (C) \\
\hline Arir & مدول برشى (كيلوياسكال) (G) \\
\hline
\end{tabular}

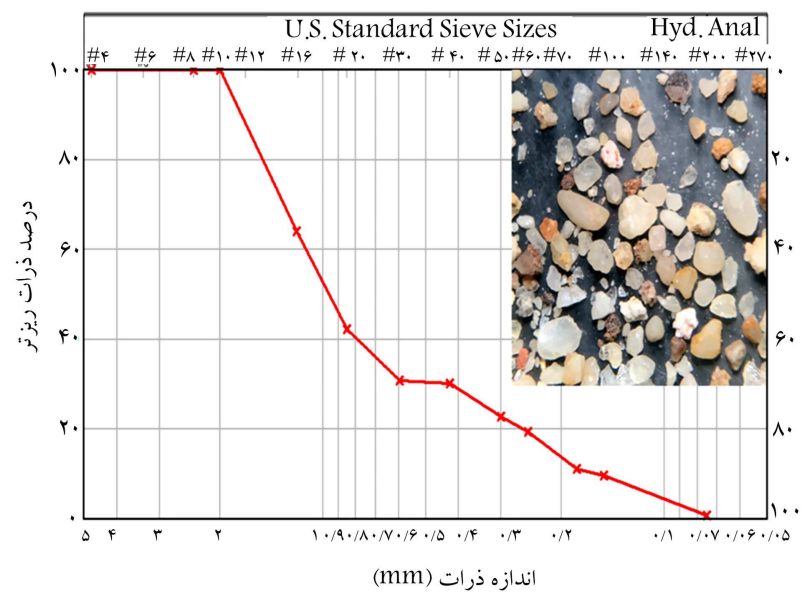

شكل ا. نتايج آزمايش دانهبندى روى ماسه به همراه تصوير دانههاى آن زير

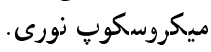

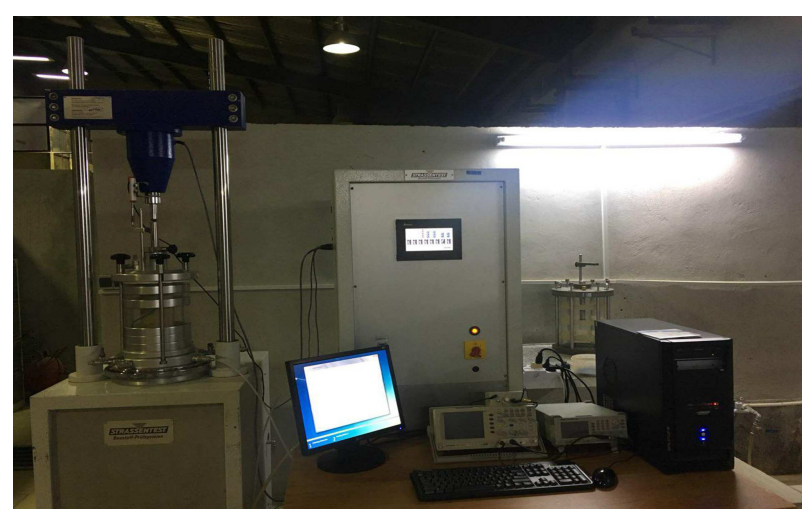

شكل r. ( دستكاه سه محورى.

را بهدست آورد. روش بارش به دو بارامتر بستى دارد، يكى شدت بارش (ميزان

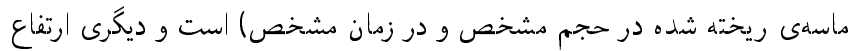

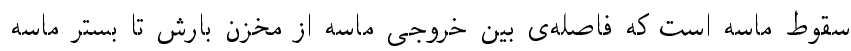

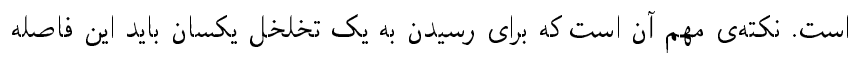

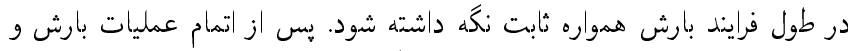

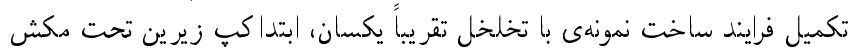

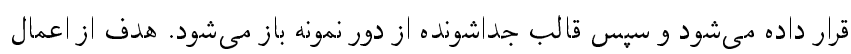

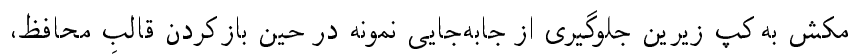

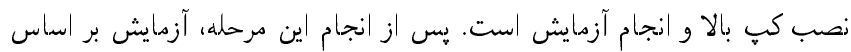

توان باربرى خاك است. [19-1\%] نتايج بروهش شمسى و مقدس تفرشى [r/] نشان

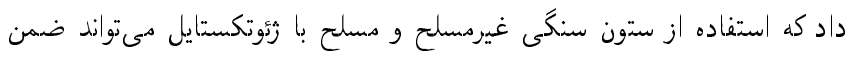

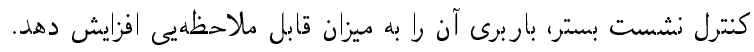

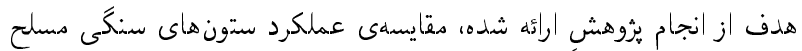

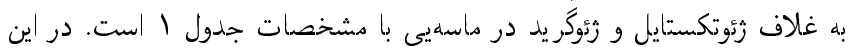

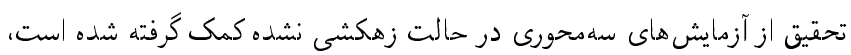

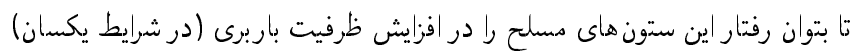

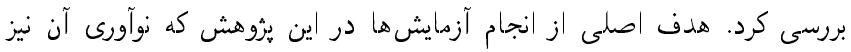

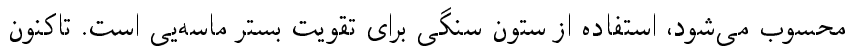

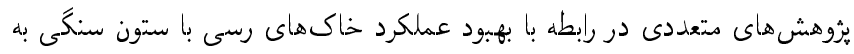

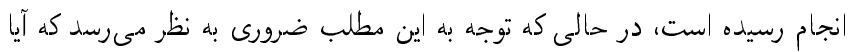

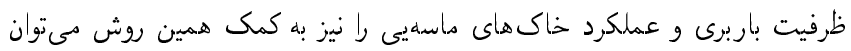

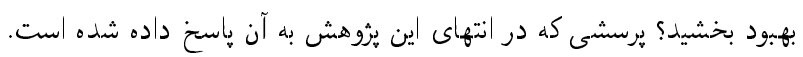

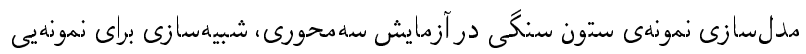

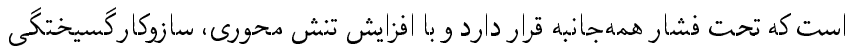

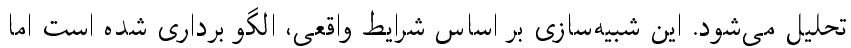

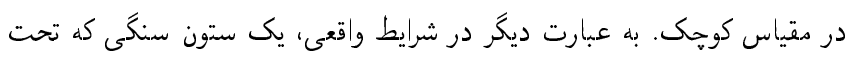

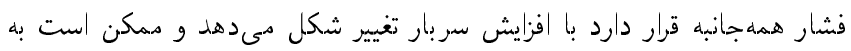

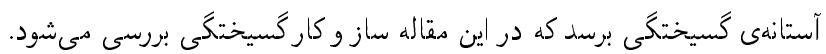

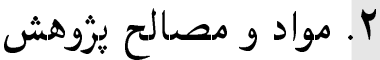

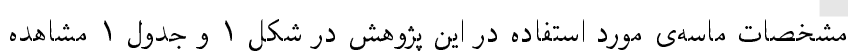

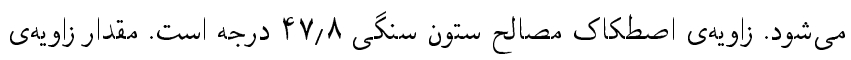

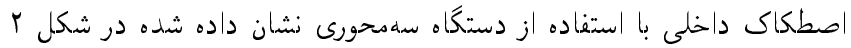

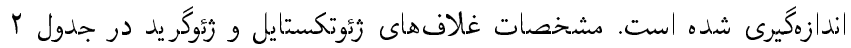

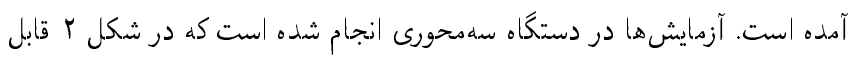

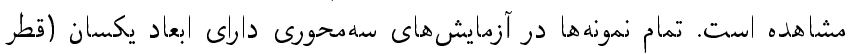

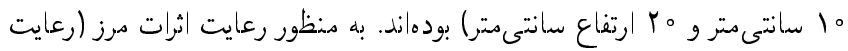

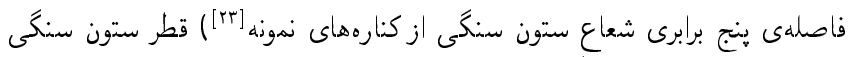

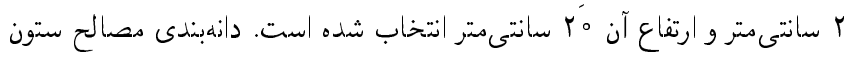

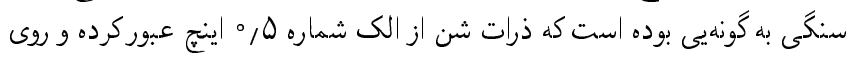

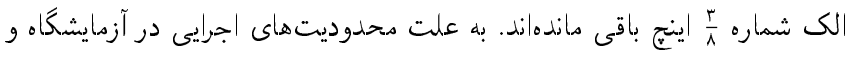

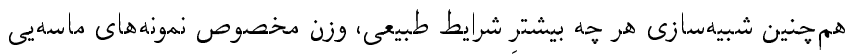

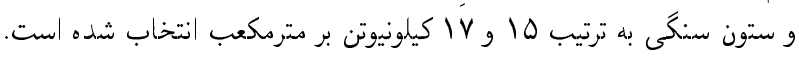

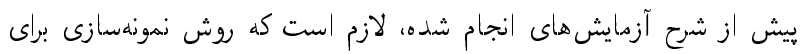

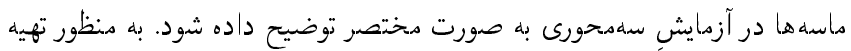

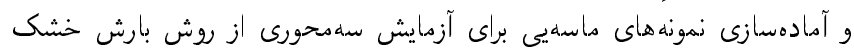

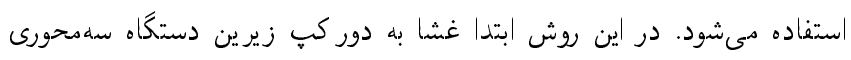

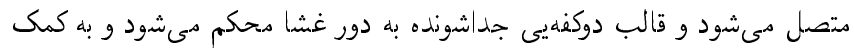

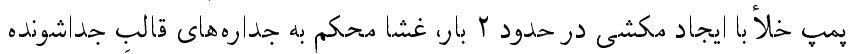

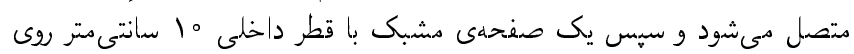

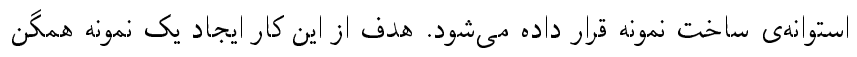

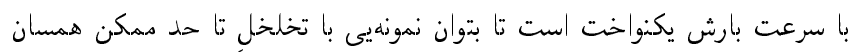




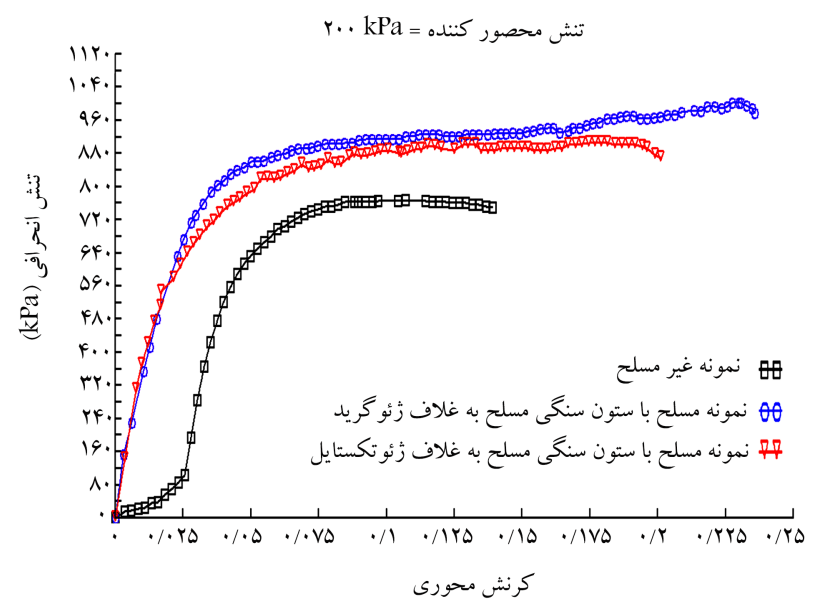

شكل ه. نمودار تنش ـ كرنش در شرايط تنش محصوركنندهى ه م كيلوياسكال.

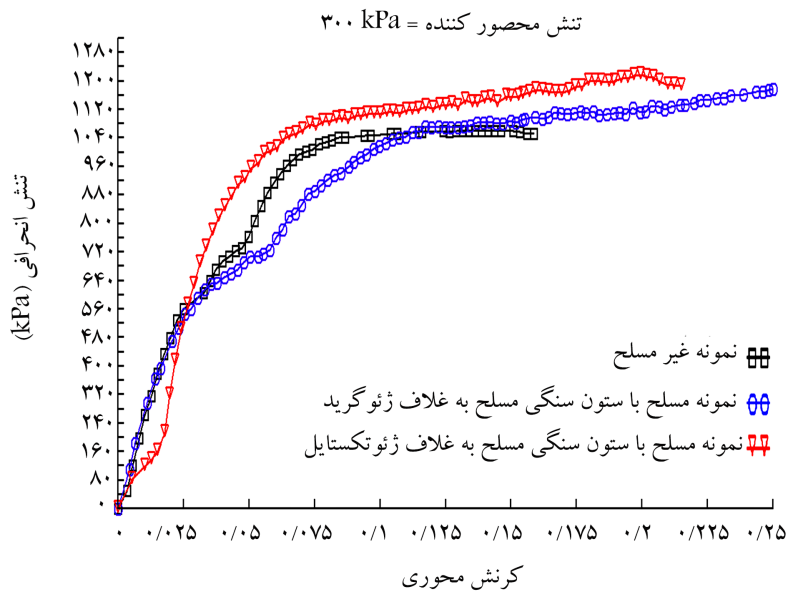

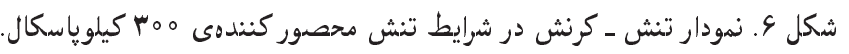

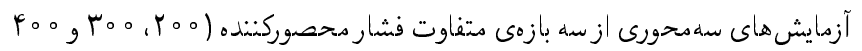

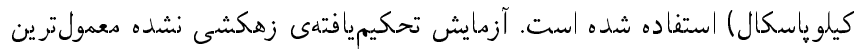

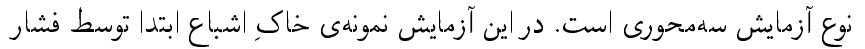

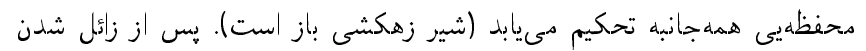

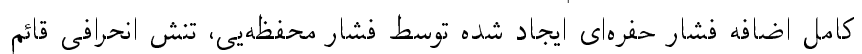

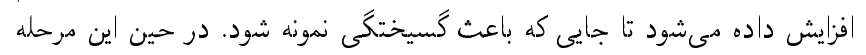

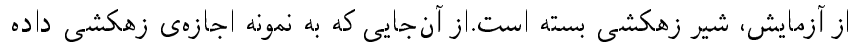

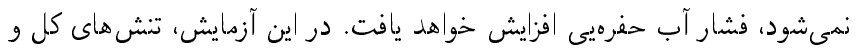

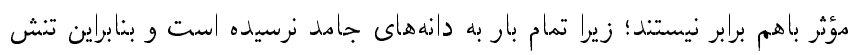
كل حاكم خواهد بود. درشكل هاى ه تا V نمودارهاى تنش _كرنش براى حالات مختلف و در شكل 1 و

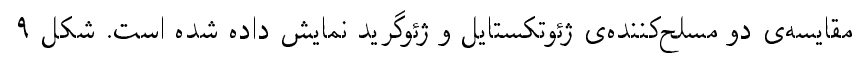

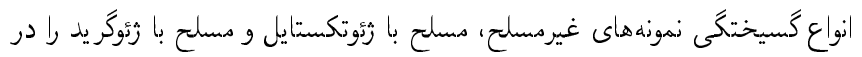

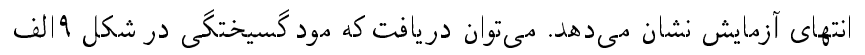

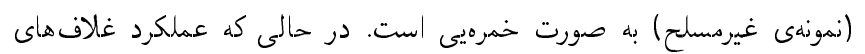

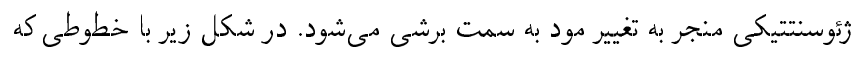

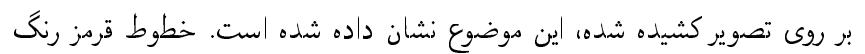

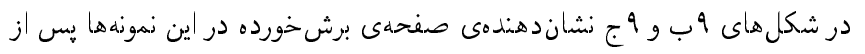

جدول r. مشخصات رئوتكستايل و رئوكر يد.

\begin{tabular}{|c|c|}
\hline \multicolumn{2}{|c|}{ لايهى رثئوتكستايل } \\
\hline$r, r$ & ضخامت ميلى متر (t) \\
\hline roo & وزن (g/cm) \\
\hline PET & نوع دصالح \\
\hline
\end{tabular}

IV

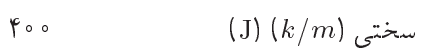

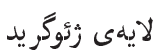

\begin{tabular}{|c|c|}
\hline$C E \backslash Y \backslash C$ & نام مدل \\
\hline $9 \times 1$ & ابعاد حشمه (mm) \\
\hline$v r^{\circ}$ & وزن (g/cm) \\
\hline
\end{tabular}

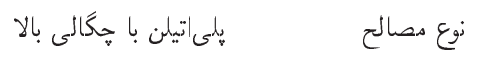

لمقاومت كششى نهايى (k/m)

1000 (J) $(k / m)$ سختى

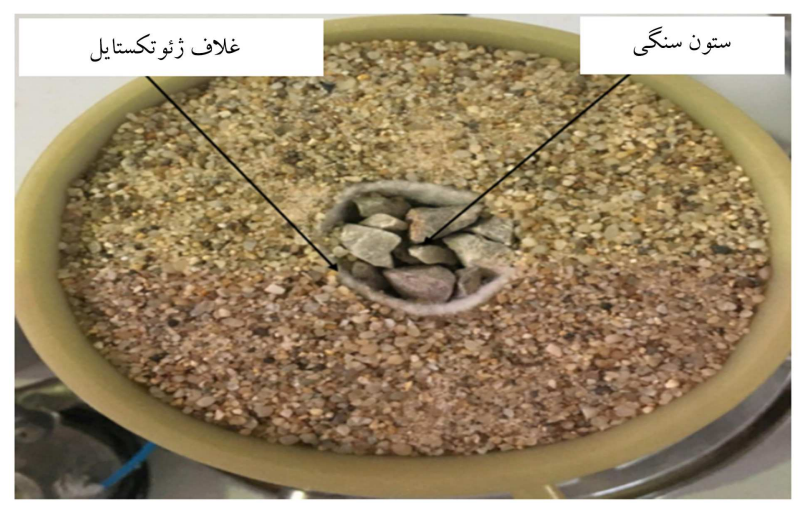

شكل r. ساخت ستون سنكى مسلح با غلاف رئوتكستايل در آزمايش سه محورى.

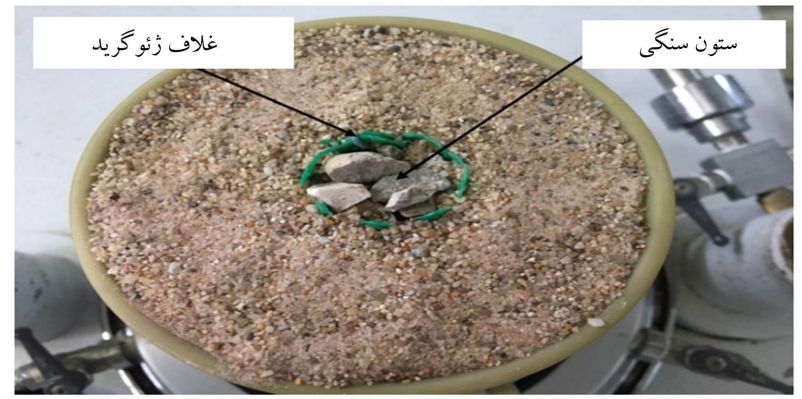

شكل Fا. ساخت ستون سنكى مسلح با غلاف رئوكً يد در آزمايش سه محورى.

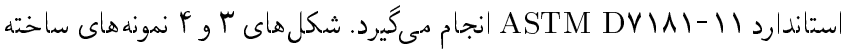

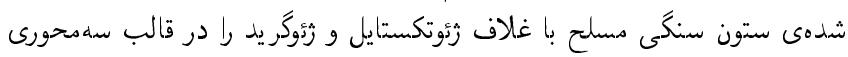
نشان مىدهند.

r. آزمايش هاى ازجام شده در اين بخش نتايج آزمايش هاى سهدحورى در شرايط زهكشى نشده (آزمايش CU)

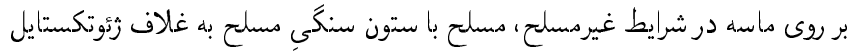

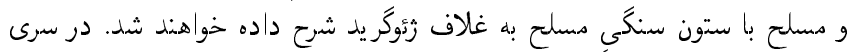




\begin{tabular}{|c|c|c|c|c|c|c|}
\hline \multirow{2}{*}{\multicolumn{3}{|c|}{ غيرمسلح }} & \multicolumn{4}{|c|}{ ستون مسلح با غلاف } \\
\hline & & & \multicolumn{2}{|c|}{ رئوتكستايل } & \multicolumn{2}{|c|}{ رئوگُ يد } \\
\hline $\begin{array}{c}\sigma_{r} \\
(k P a)\end{array}$ & $\begin{array}{c}\sigma_{1} \\
(k P a)\end{array}$ & $\begin{array}{c}\Delta \sigma_{d} \\
(k P a)\end{array}$ & $\begin{array}{c}\sigma_{1} \\
(k P a)\end{array}$ & $\begin{array}{c}\Delta \sigma_{d} \\
(k P a)\end{array}$ & $\begin{array}{c}\sigma_{1} \\
(k P a)\end{array}$ & $\begin{array}{c}\Delta \sigma_{d} \\
(k P a)\end{array}$ \\
\hline roo & $Q \varphi V, V \varphi$ & $V G \vee, V G$ & $11 \circ \Delta, r v$ & $q \circ \Delta, r v$ & $|r \circ r, r|$ & $100 r, \mu 1$ \\
\hline roo & $|r s 0,9|$ & 1090,91 & 1011,49 & $|r| 1,4 q$ & $\mid q v q, 01$ & $\mid 1 v 9,01$ \\
\hline roo & 1100,09 & 1400,09 & $1 V 90,1 \mathrm{r}$ & $1 r \Delta q, \wedge r^{*}$ & 1999,01 & 1099,01 \\
\hline $\begin{array}{c}\sigma_{\psi} \\
(k P a)\end{array}$ & \multicolumn{2}{|c|}{$\begin{array}{c}\text { غيرمسلح/ثئوتكستايل } \\
\text { (\%) }\end{array}$} & \multicolumn{2}{|c|}{ غيرمسلح/رئوكُ يد } & \multicolumn{2}{|c|}{$\begin{array}{c}\text { رئوتكستايل/رئوگر يد } \\
\text { (\%) }\end{array}$} \\
\hline roo & 1,14 & 1,11 & $1, F y$ & $1, \pi 1$ & 1,09 & 1,11 \\
\hline roo & $1,1 r$ & 1,10 & 1,09 & 1,11 & $0,9 \mathrm{~V}$ & $0,9 \mathrm{~V}$ \\
\hline roo & 0,91 & $0,9 v$ & 1,10 & $1,1 r$ & $1,1 r$ & 1,10 \\
\hline
\end{tabular}

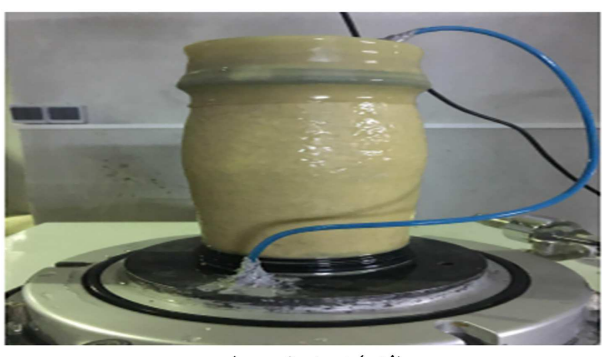

الف) نمونه غير مسلح؛

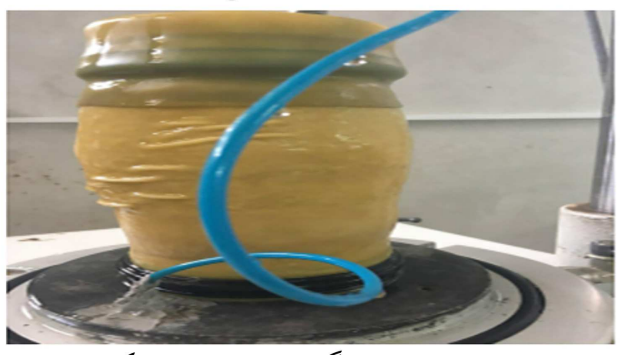

ب) نمونه مسلح با ستون سنخى مسلح با غلاف زئوتكستايل؛

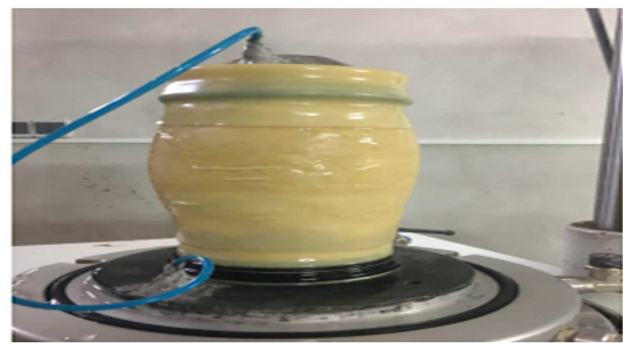

ج) نمونه مسلح با ستون سنخى مسلح با غلاف زئو گريد.

$$
\text { شكل 9. انواع گسيختكى ها. }
$$

آزمايش است. شكل هاى 9 ب و و ج مر بوط به ستونهاى سنكى مسلح با غلافهاى

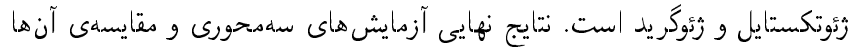

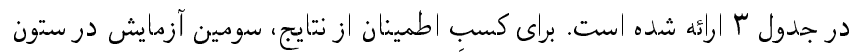

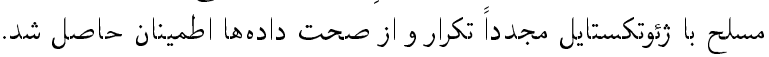

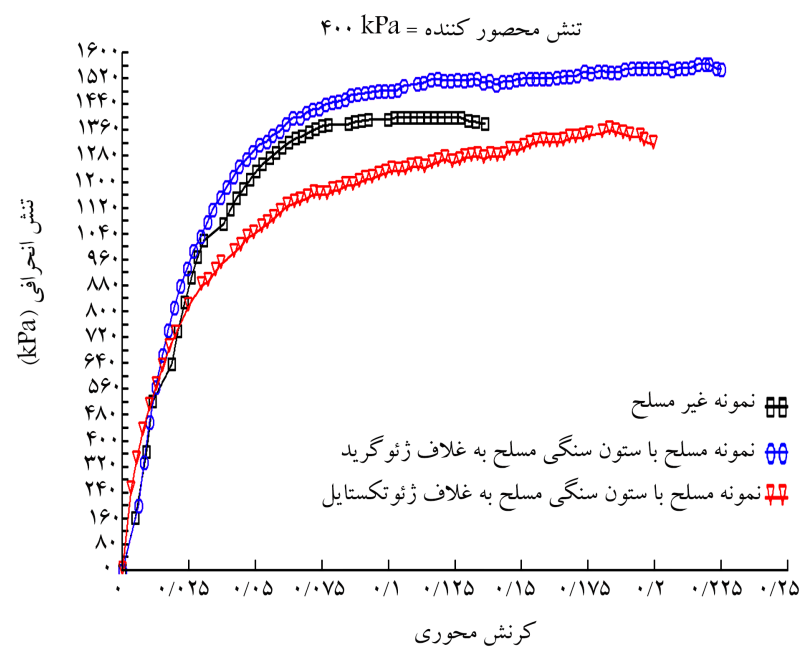

شكل V. نمودار تنش ـ كرنش در شرايط تنش محصوركنندهى محرى كيلوياسكال.

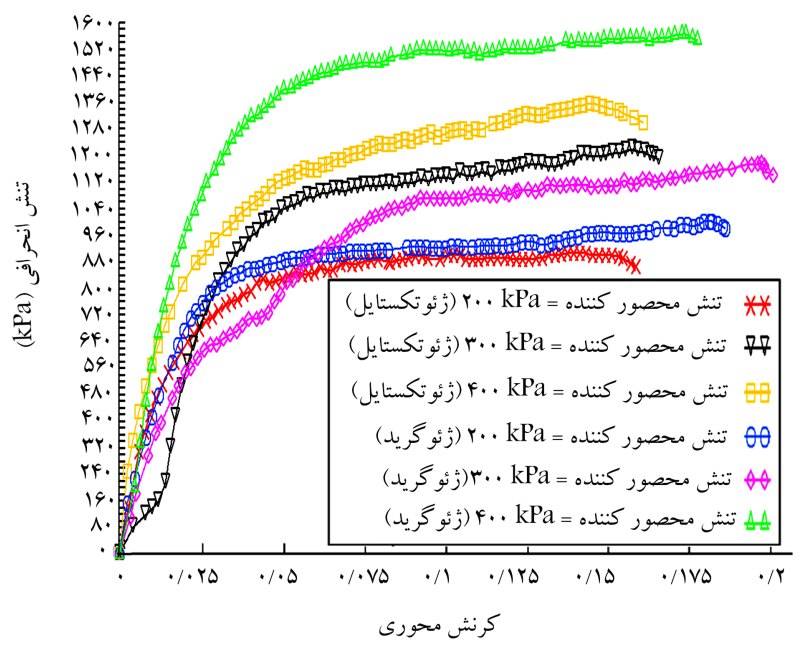

شكل ^. مقايسهى نمودار تنش -كرنش براى ستون هاى مسلح با غلافهاى رئوتكستايل و رئوكً يد. 


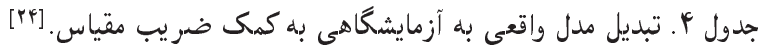

\begin{tabular}{|c|c|c|c|c|c|}
\hline جرم & نيرو & مساحت & طول & زمان & \\
\hline M & $\mathrm{F}$ & A & $\mathrm{L}$ & $\mathrm{T}$ & lo \\
\hline$S^{\iota} M$ & $S^{r} F$ & $S^{r} A$ & $\mathrm{SL}$ & $\sqrt{S T}$ & مدل آزمايشكاهى \\
\hline
\end{tabular}

مىكند؛ هرجند كه آزمايش هاى بزرك مقياس كتترل بهترى در مورد بارامترهاى كليدى

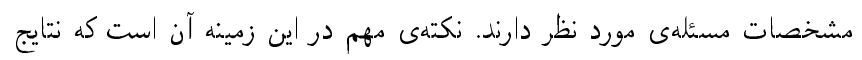

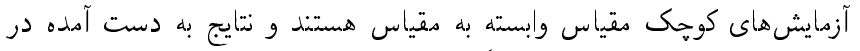

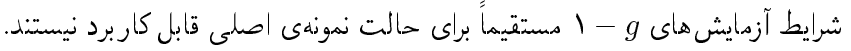

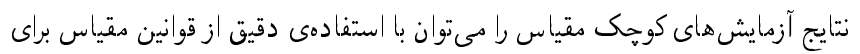

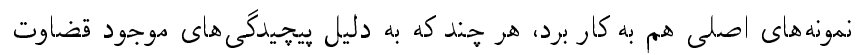

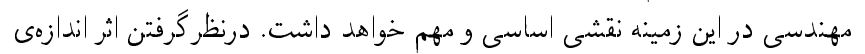

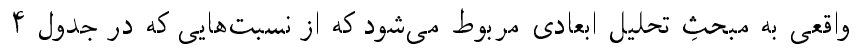

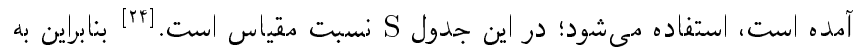

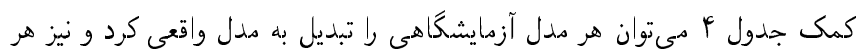

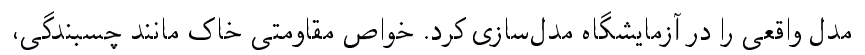

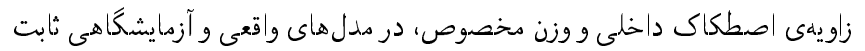

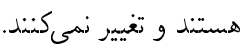

r.r.r.r. مقايسهى نتايج يزوهش ارائه شده و تحقيقات ميرندا و داكوستا [יا'

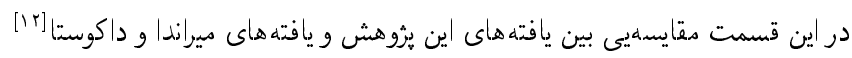

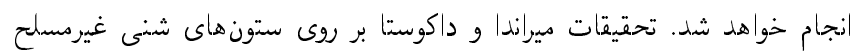

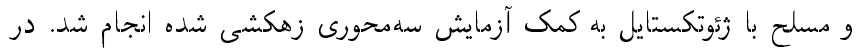

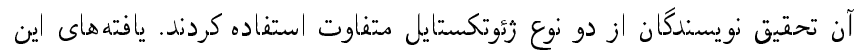

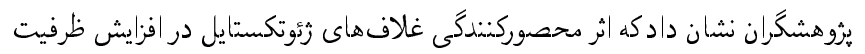

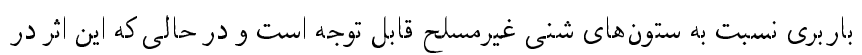

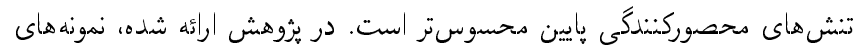

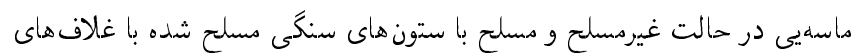

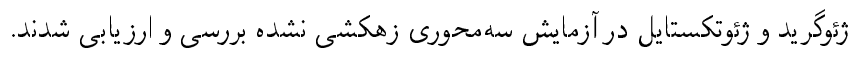

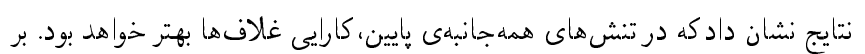

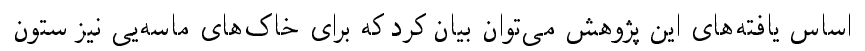

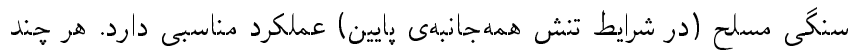

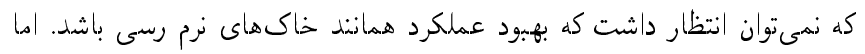

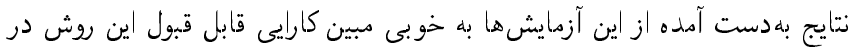
افزايش ظرفيت باربرى ماسههاست.

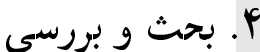

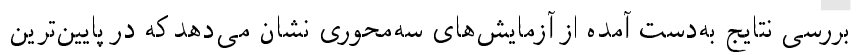

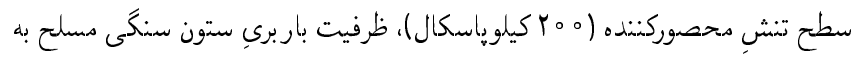

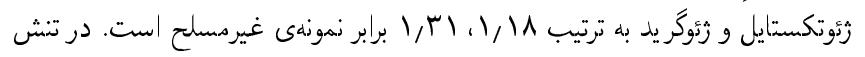

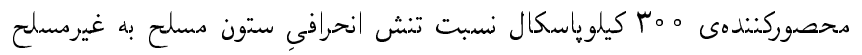

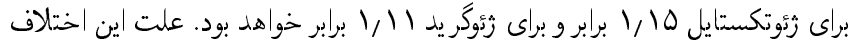

با توجه به ماهيت خاكهاى ماسهيى (كه ريزشى هستند)، با استفاده از غلاف

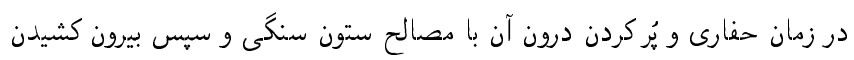

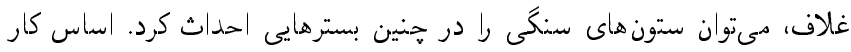

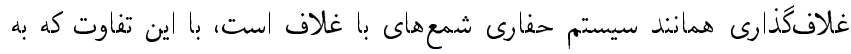

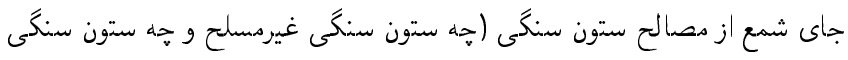

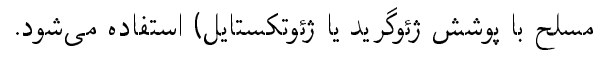

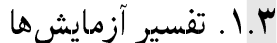

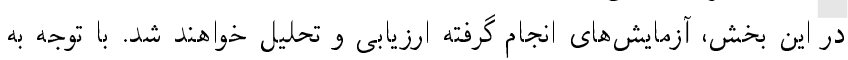

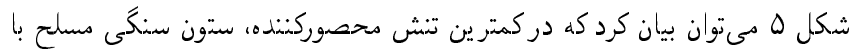

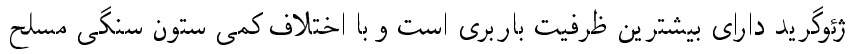

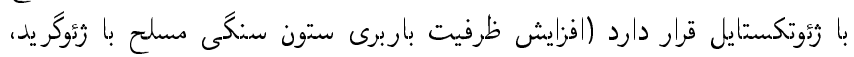

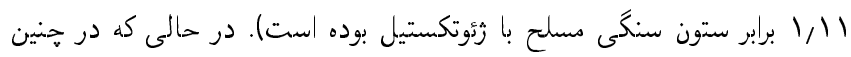

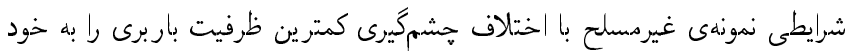

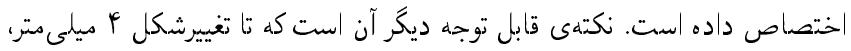

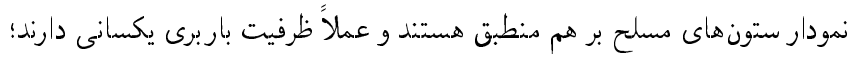

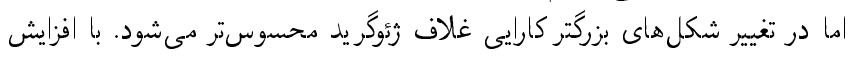

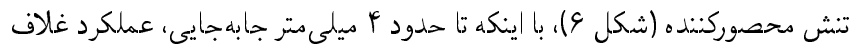

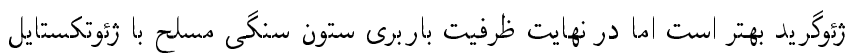

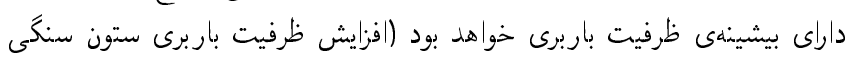

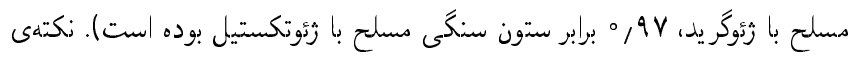

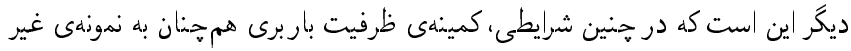

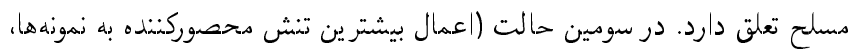

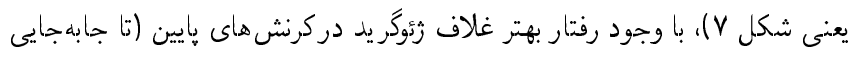

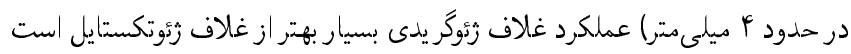

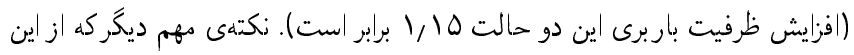

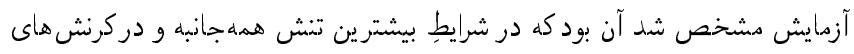

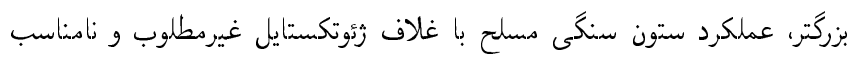

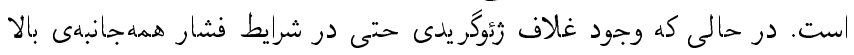

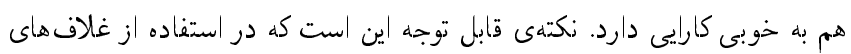

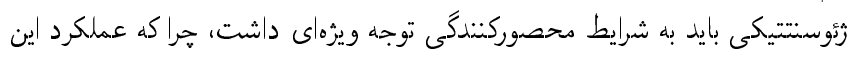

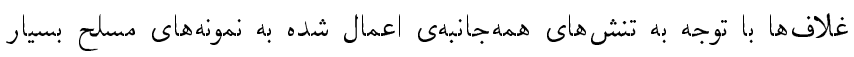

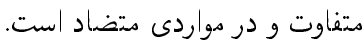

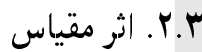
در اين بخش به بررسى اثرات مقياس و نتش آن در نتايج آزمايش ها برداخته مى شئود.

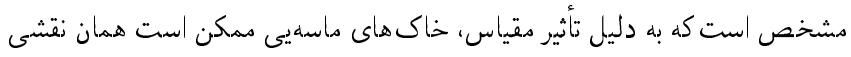

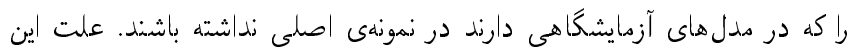

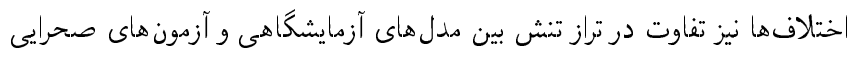

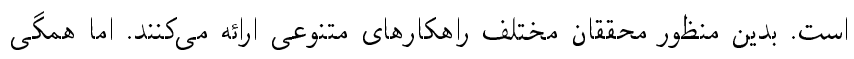

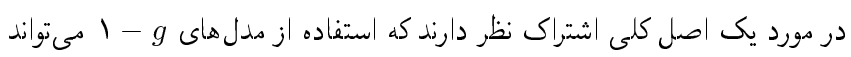

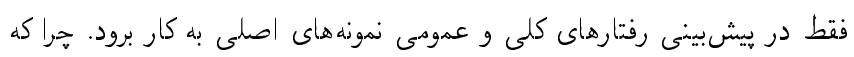

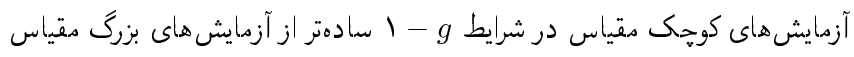

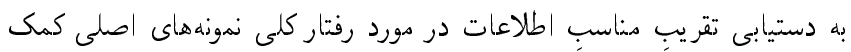


قابل توجه است و فقدان فشار همهجانبه را جبران خواهد كرد. علت عملكرد بهتر

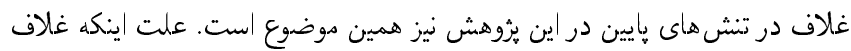

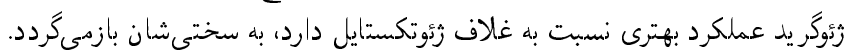

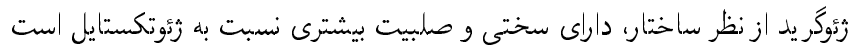

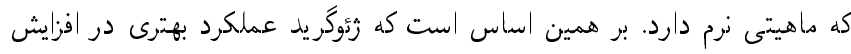

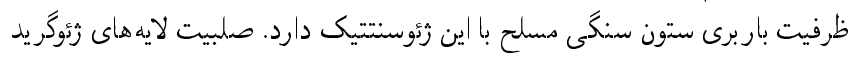

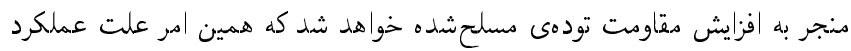

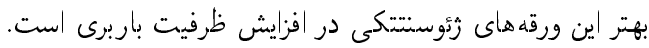

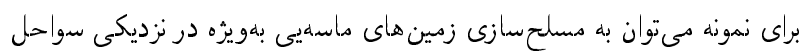

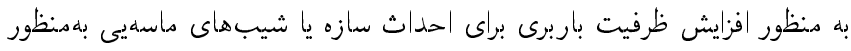

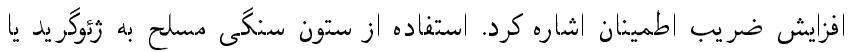
زئوتكستايل موجب افزايش ظرفيت باربرى در زمين هاى ماسهيى و ضر يب اطنان اطمينان

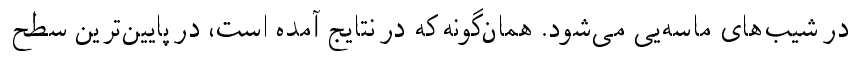

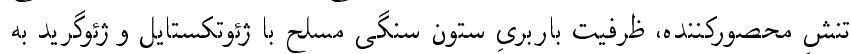

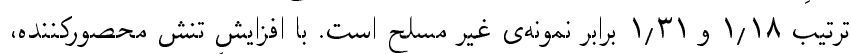

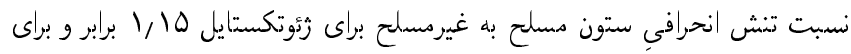

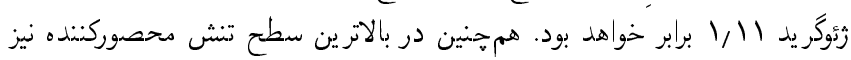

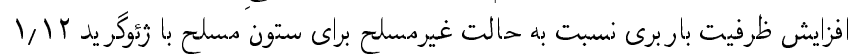
برابر بوده است.

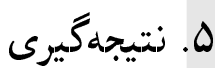

بر اساس يافتهاى اين يثوهش كه با استفاده از تعدادى آزمايش سهدحورى بر روى ماسه

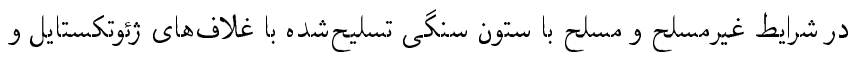

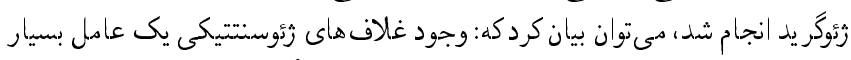

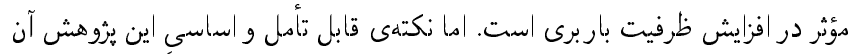

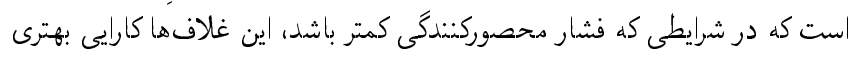

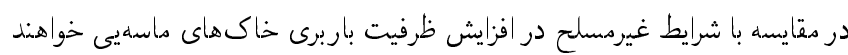

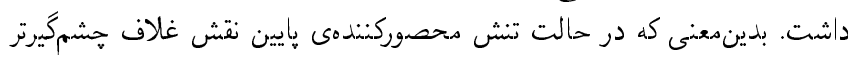

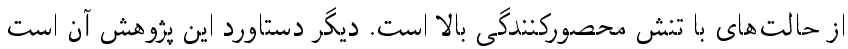

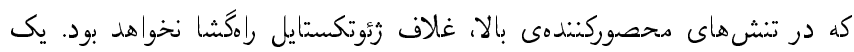

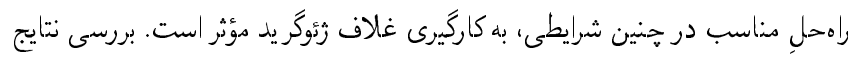

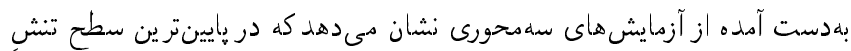

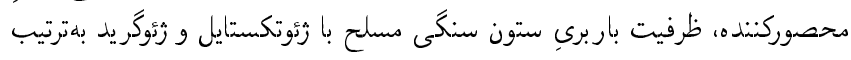

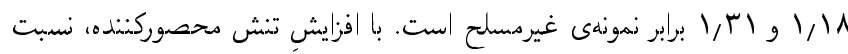

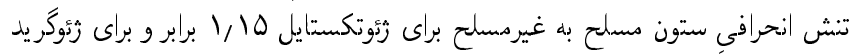

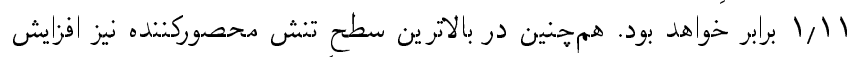

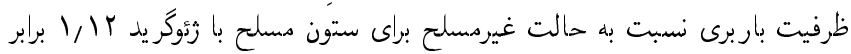
بوده است.

\section{منابع (References)}

1. Hajiazizi M. and Nasiri M., "Experimental studies on cohesion effect on stability of soil slopes reinforced
جزئى را شايد بتوان با ابعاد سنگدانهاى ستون سنكى توجيه كرد؛ هرا كه شن

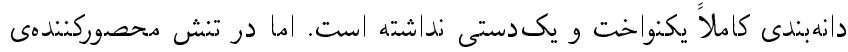

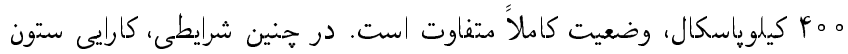

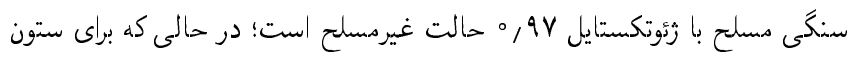

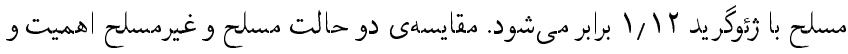

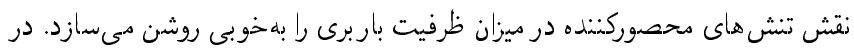

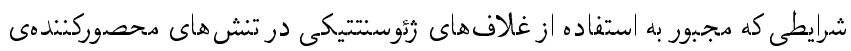

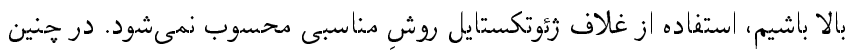

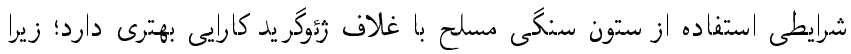

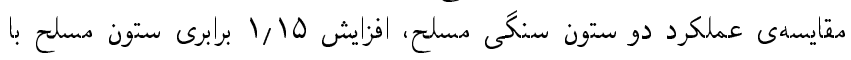

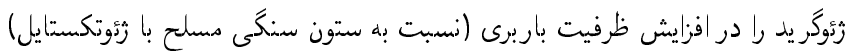

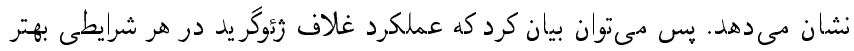
از غلاف زئوتكستايل خواهد بود.

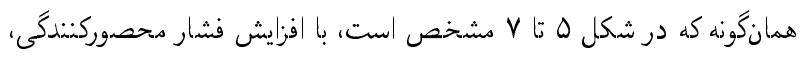

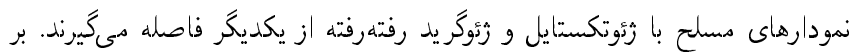

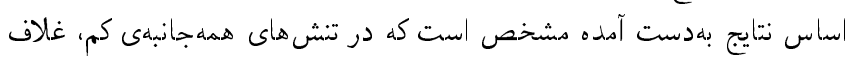

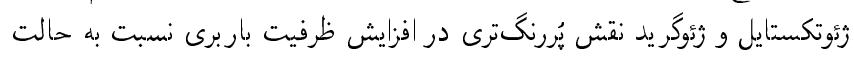

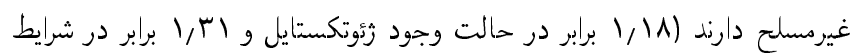

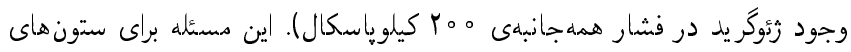

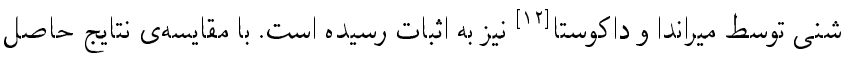

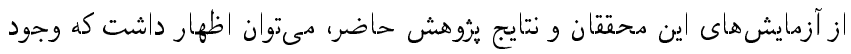

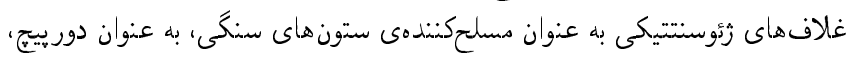

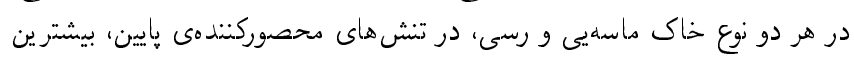

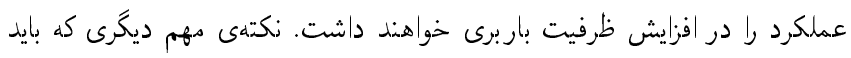

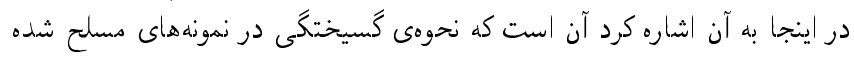

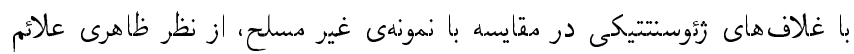

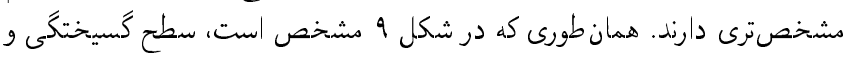

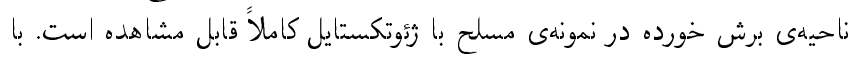

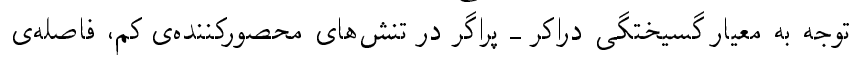

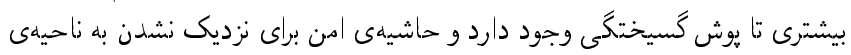

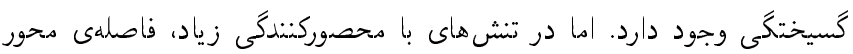

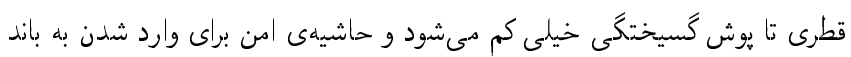

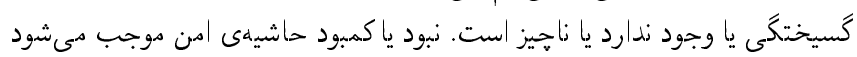

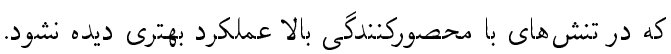

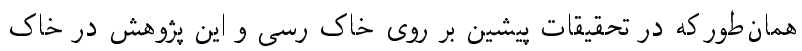

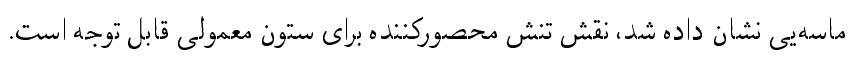

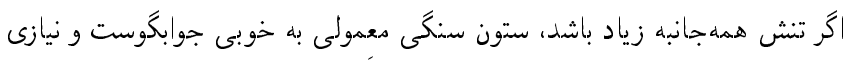

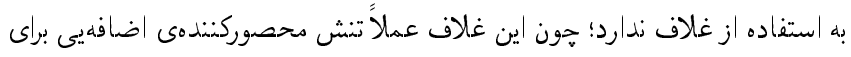

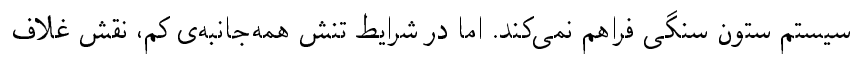

with stone column", Modares Civil Engineering Journal (M.C.E.J), 16(5), pp. 65-78, (In Persian) (2016).

2. Moghaddas Tafreshi, S.N. and Ahmadian, A.F. "Experimental investigation of the behaviour of sand-EPS 
beads mixture reinforced by Geotextile layers encapsulated with lens layers", Sharif Journal of Civil Engineering, 36.2(1.1), pp.57-68 (In Persian) (2020).

3. Hajiazizi M. and Nasiri M., "Experimental and numerical study of earth slope reinforcement using ordinary and rigid stone columns." International Journal of Mining \& Geo-Engineering, 52(1), pp .23-30 (2018).

4. Tandel Y.K., Solanki C.H. and Desai, A.K. "Field behavior geotextile reinforced sand column", Geomechanics and Engineering, 6(2), pp. 195-211 (2014).

5. Tavangar Y. and Shooshpasha, I. "Experimental and numerical study of bearing capacity and effect of specimen on uniform sand with medium density, reinforced with nonwoven geotextile", Arabian Journal for Science and Engineering, 41, pp. 4127-4137 (2016).

6. Hong Y.S., Wu C.S. and Yu Y.S. "Model tests on geotextile-encased granular columns under $1-\mathrm{g}$ and undrained conditions", Geotextiles and Geomembranes, 44(1), pp. 13-27 (2016).

7. Keyghobadi, M.H. Asakereh, A. Kalantari, B. and et al. "Experimental investigation of ring footing on reinforced soil with granulated rubber and geogrid under repeated loading", Sharif Journal of Civil Engineering, 35(2), 4353 (In Persian) (2020).

8. Lai H.J., Zheng J.J., Zhang J. and et al. "DEM analysis of "soil"-arching within geogrid-reinforced and unreinforced pile-supported embankments", Computers and Geotechnics, 61, 13-23 (2014).

9. Zhang C., Jiang G., Liu X. and et al. "Arching in geogrid-reinforced pile-supported embankments over silty clay of medium compressibility: Field data and analytical solution", Computers and Geotechnics, 77, pp. 11-25 (2016).

10. Mahdi, M., Katebi, H., Moradi, Gh. and et al. "The effects of soil reinforcement with geogrid and grid-anchor systems on uplift capacity of buried pipelines", Sharif Journal of Civil Engineering, 35(2), pp. 43-53 (In Persian) (2019).

11. Zhang L. and Zhao, M. "Deformation analysis of geotextile-encased stone columns", International Journal of Geomechanics, 15(3), pp. 1-10 (2015).

12. Miranda M. and Da Costa A., "Laboratory analysis of encased stone columns", Geotextiles and Geomembranes, 44, pp. 269-277 (2016).
13. Miranda M., Da Costa, A., Castro J. and et al. "Influence of geotextile encasement on the behaviour of stone columns: Laboratory study", Geotextiles and Geomembranes, 45, pp. 14-22 (2017).

14. Hajiazizi M. and and Nasiri M., "Experimental and numerical investigation on stability of sandy slope reinforced by using geotextile reinforced stone column", Journal of Ferdowsi Civil Engineering, 32(1), pp. 55-72 (In Persian) (2019).

15. Nasiri M. and Hajiazizi, M., "Earth slopes reinforced by stone column and geotextile", Geotechnical Engineering Journal, (Article in Press) (2019).

16. Nasiri M. and Hajiazizi, M. "An experimental and numerical investigation of reinforced slope using geotextile encased stone column", International Journal of Geotechnical Engineering, 15(5), pp.543-552 (2021).

17. Gu, M., Zhao M., Zhang L., and et al. "Effects of geogrid encasement on lateral and vertical deformations of stone columns in model tests", Geosynthetics International, 23(2), pp. 100-112, (2016).

18. Gu, M., Han, J. and Zhao, M., "Three-dimensional DEM analysis of single geogrid-encased stone columns under unconfined compression: a parametric study", Acta Geotechnica, 12(3), pp. 559-572 (2017).

19. Fattah, M.Y., Zabar, B.S. and Hassan, H.A., "Experimental Analysis of Embankment on Ordinary and Encased Stone Columns", International Journal of Geomechanics, 16(4), pp. 1-13 (2016).

20. Hajiazizi, M. and Nasiri, M. "3D numerical investigation of slope stability using geogrid reinforced stone column", Amirkabir Journal of Civil Engineering, 52(3), pp.1-19 (In Persian) (2020).

21. Hajiazizi, M. and Nasiri, M. "Experimental and numerical investigation of reinforced sand slope using geogrid encased stone column", Civil Engineering Infrastructures Journal, 52(1), pp. 85-100 (2019).

22. Shamsi, M. and Moghaddas Tafreshi, S.N. "Experimental and numerical investigations on the behavior of stone column reinforced by geotextile encasement and geotextile layers", Sharif Journal of Civil Engineering, 34(2), pp. 111-122 (In Persian) (2018).

23. PLAXIS Software version 8, Tutorial Manual. 